\title{
Validity of the patient health questionnaire 9-item in autistic youths: a pilot study
}

\author{
Thanita Pilunthanakul ${ }^{1 *}$ (D), Tze Jui Goh², Daniel Shuen Sheng Fung ${ }^{2}$, Rehena Sultana ${ }^{3}$, John Carson Allen ${ }^{3}$ and \\ Min Sung ${ }^{2}$
}

\begin{abstract}
Background: Autistic adolescents have greater predisposition to depression and suicidality than neurotypical adolescents. Early detection is essential for timely treatment. The Patient Health Questionnaire 9-item (PHQ-9) is a brief screen for depression. The study examines the validity of the PHQ-9 for detecting major depressive disorder (MDD) in autistic youths.

Methods: English speaking youths aged 10-18 years, with DSM-IV/DSM-5/ICD-10 diagnosis of Autism Spectrum Disorder (ASD), and their parents presenting to a child psychiatric service were invited to participate between May 2018 to August 2020. Participants completed the respective self- and parent-rated PHQ-9 independently. MDD was verified using the MINI-Kid (Mini-International Neuropsychiatric Interview, Kid version).

Results: One hundred one youth, mean (SD) age 14.6 (2.3), were enrolled. 27 (27\%) met criteria for current MDD. Mean total PHQ-9 scores, percentage ratings for severity of symptoms of depression, functional impairment, dysthymia and suicidality were compared. Areas under the ROC curve and statistically optimal cutoffs were determined. Parents rated depressive symptoms severity lower than their children. The PHQ-9 displayed low sensitivity with high false negative rates at conventional, adjusted and proposed cutoffs.

Conclusions: Future studies should improve on the validity and reliability of existing depression screening tools, or develop more appropriate screening methods of depression, for autistic youths.
\end{abstract}

Keywords: Depression adolescent PHQ-9 autism ROC

\section{Background}

Depression is a common comorbid psychopathology in autism spectrum disorders (ASD) [1, 2]. A prospective study over a period of $1-5$ years investigating psychiatric comorbidities in autistic youths aged 6 to 20 years reported that $42 \%$ had experienced an increase in expression of suicidal behaviors from childhood to adolescence, and of the 30\% that suffered from major depressive disorder (MDD), 20\% exhibited severe suicidal behavior or had attempted suicide [3].

\footnotetext{
* Correspondence: thanita33@gmail.com

${ }^{1}$ Ministry of Health, 16 College Rd, College of Medicine Building, Singapore 169854, Singapore

Full list of author information is available at the end of the article
}

Screening for depression is essential for early detection and treatment. Families of autistic patients are more likely to make frequent primary care visits [4], thus, primary care physicians play an important role in diagnosis, and prompting early intervention for depression-especially for patients and families who may not seek psychiatric care. Current tools used to assess depression in autistic youths may be inappropriate for outpatient healthcare settings as they may be costly, timeconsuming, involve extensive scoring processes and/or an additional psychiatric specialist assessment [5-8].

The Patient Health Questionnaire 9-item (PHQ-9) is a widely used depression screen $[9,10]$ in primary care, outpatient, and research settings with good reliability

(c) The Author(s). 2021 Open Access This article is licensed under a Creative Commons Attribution 4.0 International License, which permits use, sharing, adaptation, distribution and reproduction in any medium or format, as long as you give appropriate credit to the original author(s) and the source, provide a link to the Creative Commons licence, and indicate if changes were made. The images or other third party material in this article are included in the article's Creative Commons licence, unless indicated otherwise in a credit line to the material. If material is not included in the article's Creative Commons licence and your intended use is not permitted by statutory regulation or exceeds the permitted use, you will need to obtain permission directly from the copyright holder. To view a copy of this licence, visit http://creativecommons.org/licenses/by/4.0/ The Creative Commons Public Domain Dedication waiver (http://creativecommons.org/publicdomain/zero/1.0/) applies to the data made available in this article, unless otherwise stated in a credit line to the data. 
and validity. It is brief, user-friendly, easy to administer, and available in parent- and self-reported formats. Furthermore, the PHQ-9 promptly categorizes the severity level of depressive symptoms and is available without cost, making it effective for busy healthcare settings. The PHQ-9 has shown good validity in neuro-typical adolescents [11], in a multi-ethnic Asian sample such as those in Singapore [12] and in autistic adults [13]. However, no study has investigated its utility and optimal cutoff in autistic youths as yet.

This study aims to determine the optimal cutoffs for the self- and parent-reported PHQ-9 screen for MDD (as verified by the Mini-International Neuropsychiatric Interview, Kid version [MINI-Kid]) in autistic youths. We hypothesize that different cutoffs (compared to neuro-typical adolescents) may be needed to exclude MDD in autistic youths, while maintaining an acceptable false positive/negative rate, since clinical symptoms of ASD may overlap with core symptoms of depression (e.g., sleep disturbances, abnormal eating habits, psychomotor retardation and irritability) [14]. Secondary aims include determining internal consistency and convergent validity between the self- and parent-rated PHQ-9 and investigating possible correlations between participant characteristics and severity of functional impairment and depressive symptoms in autistic youths.

\section{Method}

\section{Participants}

Patients who attended consultations at the outpatient Child Guidance Clinic (CGC), Institute of Mental Health (IMH), Singapore, from May 2018 to August 2020 were invited to participate in the study if they fulfilled the following inclusion criteria: (i) aged 10 to 18 years, (ii) diagnosed with ASD based on the Diagnostic and Statistical Manual, 5th (DSM-5) or 4th Edition (DSMIV), or International Statistical Classification of Diseases and Related Health Problems, 10th Revision (ICD-10), by a registered psychiatrist, (iii) a Clinical Evaluation of Language Fundamentals, 5th Edition, Screening Tool (CELF-5) [15], age equivalent score above 8 years of age to ensure comprehension of questions on the PHQ-9, and (iv) parental consent and agreement to participate. The exclusion criteria were as follows: (i) patients who were unable to speak, non-responsive, non-communicative or had not acquired language, ii) patients with co-occurring Intellectual Disability, and (iii) caregivers who were unable to read and understand English.

The a priori sample size was predicated on the assumption of $15 \%$ MDD prevalence [1]. Our intention was to recruit 100 ASD patients, of which 15 were expected to have MDD, in order to achieve $\geq 80 \%$ power at $\alpha=0.05$ to detect target sensitivity of $86 \%$.

\section{Materials}

The PHQ-9 [16] is a multipurpose instrument used in screening, diagnosing and monitoring the severity of depression. The optimal cutoff of 11 in neuro-typical adolescents typically indicates clinically significant depressive symptoms with $89.5 \%$ sensitivity and $77.5 \%$ specificity [11]. Respondents rate the frequency of the following nine symptoms over the previous two-week period on a four-point Likert scale (never $=0$, several days $=1$, more than half the days $=2$, nearly every day $=$ 3): depressed mood, anhedonia, sleep problems, feelings of tiredness, changes in appetite or weight, feelings of worthlessness, difficulty concentrating, feelings of sluggishness or worry and suicidal ideation. Scores of 5-9, 10-14, 15-19, and 20-27 represent mild, moderate, moderately severe, and severe depression, respectively. The PHQ-9 also has screening questions for dysthymia and suicidality, as well as a functional impairment item that examines the degree of interference with daily functioning due to the indicated symptoms.

The MINI-Kid [17] is a structured diagnostic interview for DSM-5 disorders in children and adolescents. It can be administered in a shorter time with similar validity and reliability compared to extended clinical interviews like the Kiddie Schedule for Affective Disorders and Schizophrenia and has high interrater reliability. Studies have used the MINI-Kid to assess for comorbid psychiatric disorders in children and adolescents with ASD $[18,19]$. Patients fulfilling at least five of the DSM-5 criteria during the previous two weeks (with at least one symptom as depressed mood or loss of interest) were determined to have met criteria of MDD. Other comorbid psychiatric disorders were also assessed as part of the interview.

The demographic form included participant age, sex, ethnicity, education level, medications, relationship to child, and parental job status.

\section{Procedure}

Participants and parents who met the inclusion criteria were enrolled. After providing written informed consent, youth completed the CELF-5 conducted by a trained research team member to determine eligibility. Enrolled participants completed the demographic form and the self- and parent-rated PHQ-9 (English versions) independently. Subsequently, a research team member, trained by a qualified clinical psychologist and blinded to the PHQ-9 results, administered the MINI-Kid (English version) to both youth and parent. Recruitment, consent, and administration of all questionnaires and interviews were completed on the same day. No additional visits were required. The study protocol was approved by the Institutional Research Review Committee (CRC 
Ref 612-2018) and the National Health Group Domain Specific Review Board (DSRB Ref 2018/00352).

Receiver operating characteristic (ROC) analysis was performed to determine sensitivity, specificity, positive (PPV) and negative predictive value (NPV), and likelihood ratios for various cutoffs of the self- and parentrated PHQ-9. The Youden Index (YI; J-statistic, calculated as sensitivity + specificity -1 ) was also employed to identify a statistically 'optimal' cutoff. The reliability of the PHQ-9 versions was evaluated using Cronbach's $\alpha$. Convergent validity and associations were assessed using Pearson $(r)$ and Spearman $\left(r_{s}\right)$ correlation coefficients for continuous and ordinal variables, respectively. McNemar's test was used to compare the difference between self- and parent-reported severity of depressive symptoms, functional impairment, dysthymia, and suicidality. Statistical significance was set at $p<0.05$. Descriptive statistics and analysis were conducted using SPSS Version 24.0.

\section{Results}

The final sample consisted of 101 youth and parent pairs. Youth participants ranged in age from 9 to 18 years old, with mean (SD) age of 14.6 (2.3); CELF-5 scores ranged from 11.0 to 30.0, with mean (SD) 21 . (5.2). Participant characteristics are summarized in Table 1.

Of the 101 youths in the final sample, a total of 27 (27\%) had experienced a MDD or MDE (major depressive episode; in cases diagnosed with Bipolar Disorder), at least once in their lifetime. 19 (19\%) met the criteria for MDD, as verified by the MINI-Kid. Of these 19 cases, 12 (63\%) experienced recurrent MDEs, and/or associated suicidality and psychotic features (Fig. 1). Those currently diagnosed with MDD were subsequently flagged up to their primary psychiatrist for management.

The mean (SD) total scores for self- and parent-rated PHQ-9 were 9.0 (6.0) and 6.2 (5.6) respectively. Frequencies of depressive symptoms severity were compared between self- and parent reports $(p=0.0071)$, summarized in Fig. 2. Frequencies of dysthymia during the past year $(p=0.1228)$, suicidal thoughts in the previous month $(p=0.0522)$ and attempted suicide at least once (lifetime; $p=0.0495)$ were also compared and summarized in Fig. 3. Frequencies of functional impairment severity levels were compared and consistent between self and parent reports $(p=0.3949)$, summarized in Fig. 4 .

Table 2 lists selected cutoffs based on the ROC analyses of self- and parent-rated PHQ-9 scores for diagnosing MDD in autistic youths as verified by the MINI-Kid. ROC curves are presented in Figs. 5 and 6. The area (95\% CI) under the curve (AUC) for the parent- and self-rated PHQ-9 was $0.653(0.52-0.78, p=0.094)$ and $0.716(0.60-0.83, \quad p=0.007)$, respectively. The
Table 1 Demographic and clinical characteristics of study sample. Data contributed by author

\begin{tabular}{|c|c|}
\hline Characteristics of adolescent participants $(n=101)$ & n (\%) \\
\hline \multicolumn{2}{|l|}{ Sex } \\
\hline Male & $88(87.1)$ \\
\hline Female & $13(12.9)$ \\
\hline \multicolumn{2}{|l|}{ Ethnicity } \\
\hline Chinese & $85(84.2)$ \\
\hline Malay & $6(5.9)$ \\
\hline Indian & $4(4.0)$ \\
\hline Others & $6(5.9)$ \\
\hline \multicolumn{2}{|l|}{ Education Level } \\
\hline Primary & $11(10.9)$ \\
\hline Secondary & $66(65.4)$ \\
\hline Special Education Secondary & $13(12.9)$ \\
\hline Tertiary & $11(10.9)$ \\
\hline On psychotropic Medications & $46(45.5)$ \\
\hline \multicolumn{2}{|l|}{ Number of comorbidities (based on MINI-Kid) } \\
\hline 0 & $33(32.7)$ \\
\hline 1 & $35(34.7)$ \\
\hline 2 & $18(17.8)$ \\
\hline$>2$ & $15(14.9)$ \\
\hline Characteristics of parent participants $(n=84)$ & n (\%) \\
\hline \multicolumn{2}{|l|}{ Relationship to child } \\
\hline Mother & $84(83.2)$ \\
\hline Father & $17(16.8)$ \\
\hline \multicolumn{2}{|l|}{ Ethnicity } \\
\hline Chinese & $85(84.2)$ \\
\hline Malay & $7(6.9)$ \\
\hline Indian & $4(4.0)$ \\
\hline Other & $5(5.0)$ \\
\hline \multicolumn{2}{|l|}{ Parent's highest education level } \\
\hline Below secondary & $4(4.0)$ \\
\hline Secondary & $38(37.6)$ \\
\hline Tertiary & $59(58.4)$ \\
\hline \multicolumn{2}{|l|}{ Parent's job status } \\
\hline Unemployed & $39(38.6)$ \\
\hline Part-time & $2(2.0)$ \\
\hline Full-time & $60(59.4)$ \\
\hline
\end{tabular}

MINI-Kid, Mini International Neuropsychiatric Interview for Children and Adolescents

statistically optimal cutoffs based on the YI was 5 for the self-rated PHQ-9 with 100\% sensitivity and 35\% specificity, and 6 for the parent-rated PHQ-9 with 74\% sensitivity and 59\% specificity. For the self-rated PHQ-9 with YI cutoff of 5, the negative predictive value (NPV) was $100 \%$, and the positive predictive value (PPV) was $26 \%$; 


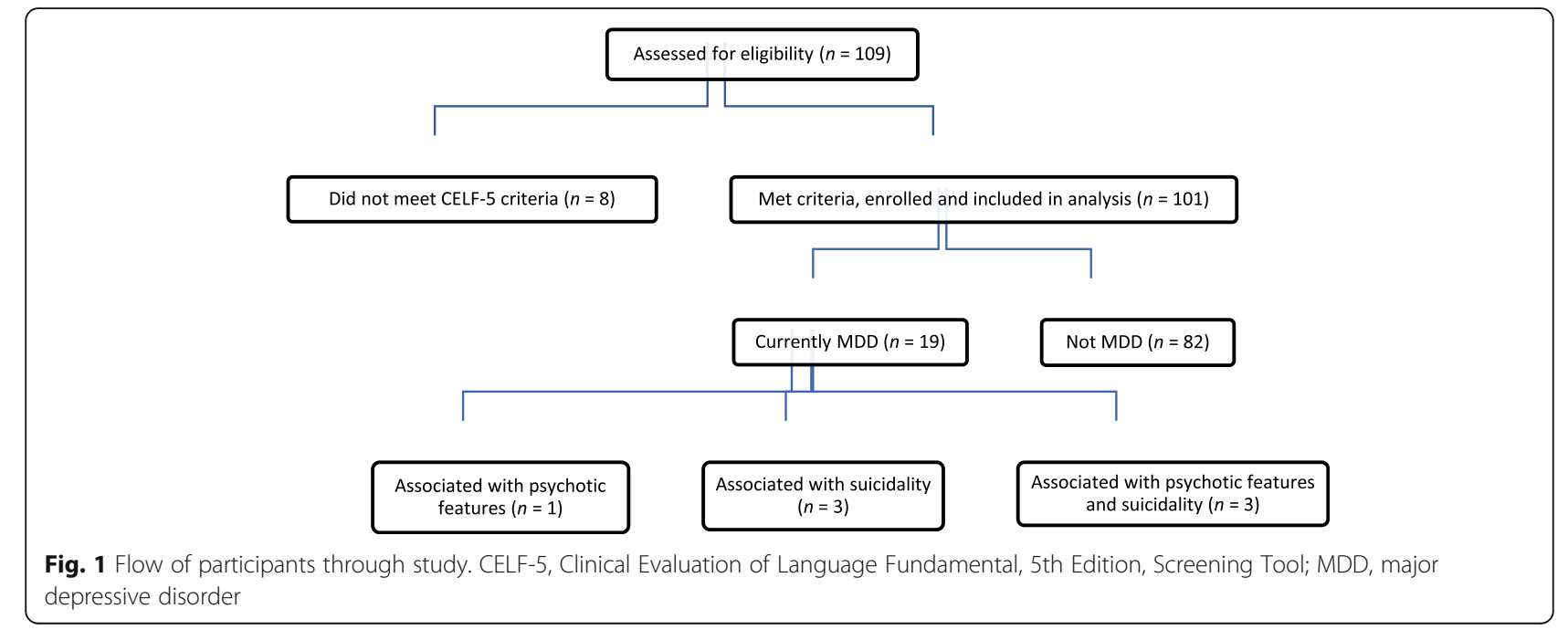

for the parent-rated PHQ-9 with YI cutoff of 6, the NPV was $91 \%$, and the PPV was $29 \%$.

Both self- and parent-rated PHQ-9 showed acceptable internal consistency, as demonstrated by the Cronbach $\alpha$ coefficients of 0.810 and 0.845 , respectively. Although statistically significant, the Pearson correlation between self- and parent-rated PHQ-9 scores would be considered weak to moderate $(r=0.491, n=101, p=0.01)$.

Spearman correlation coefficients for associations between self- and parent-rated severity of depressive symptoms and of functional impairment, and number of comorbidities are summarized in Table 3. Age and education demonstrated no significant correlation with self- or parent-rated severity of functional impairment or with depressive symptoms.

\section{Discussion}

Consistent with previous literature [6, 20,21], our study demonstrated a high co-occurrence of depression in autistic youth, emphasizing the importance of routine screening for depression. Almost half of our total sample self-reported dysthymia symptoms and at least a quarter reported suicidality. 19\% met criteria for MDD, and of

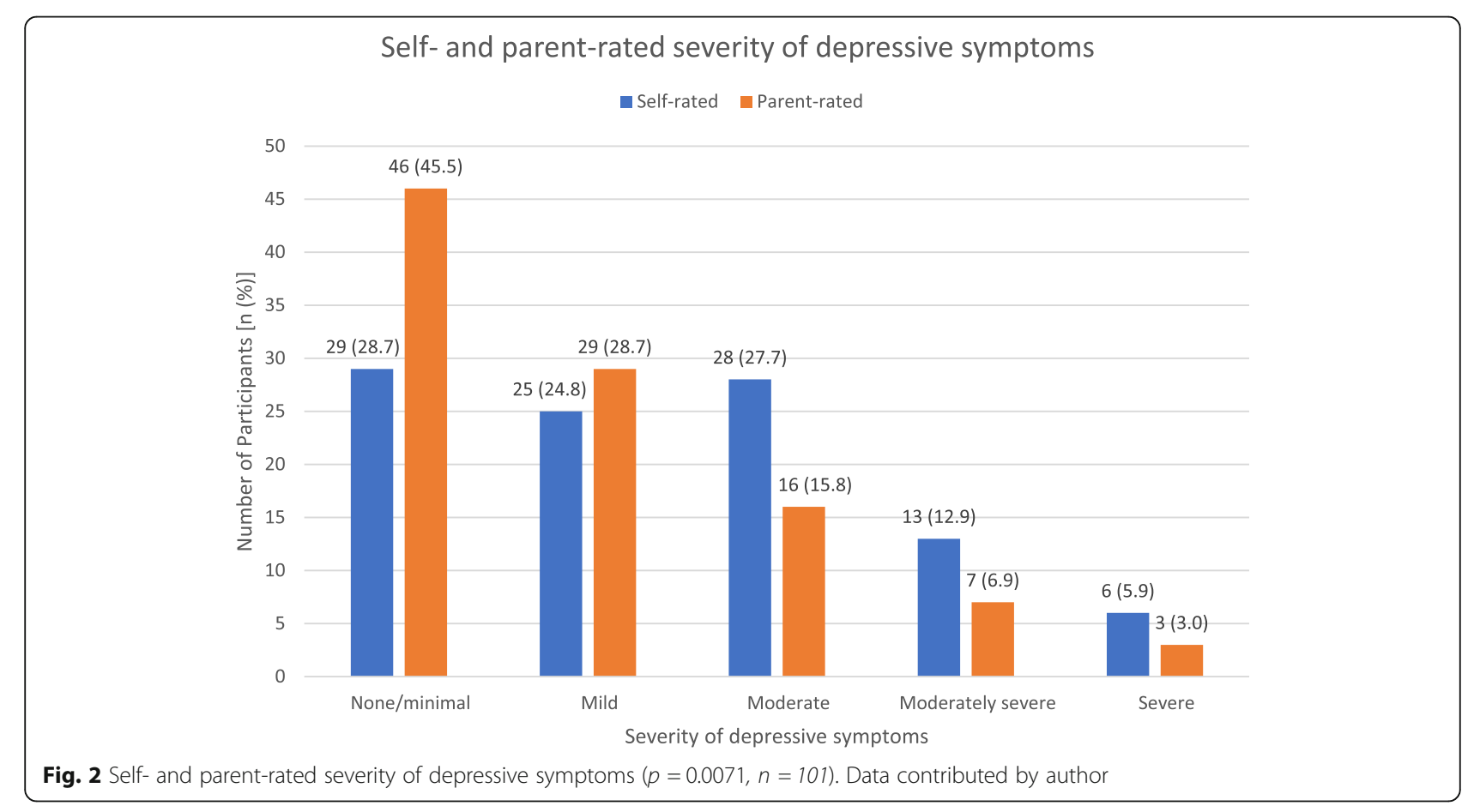




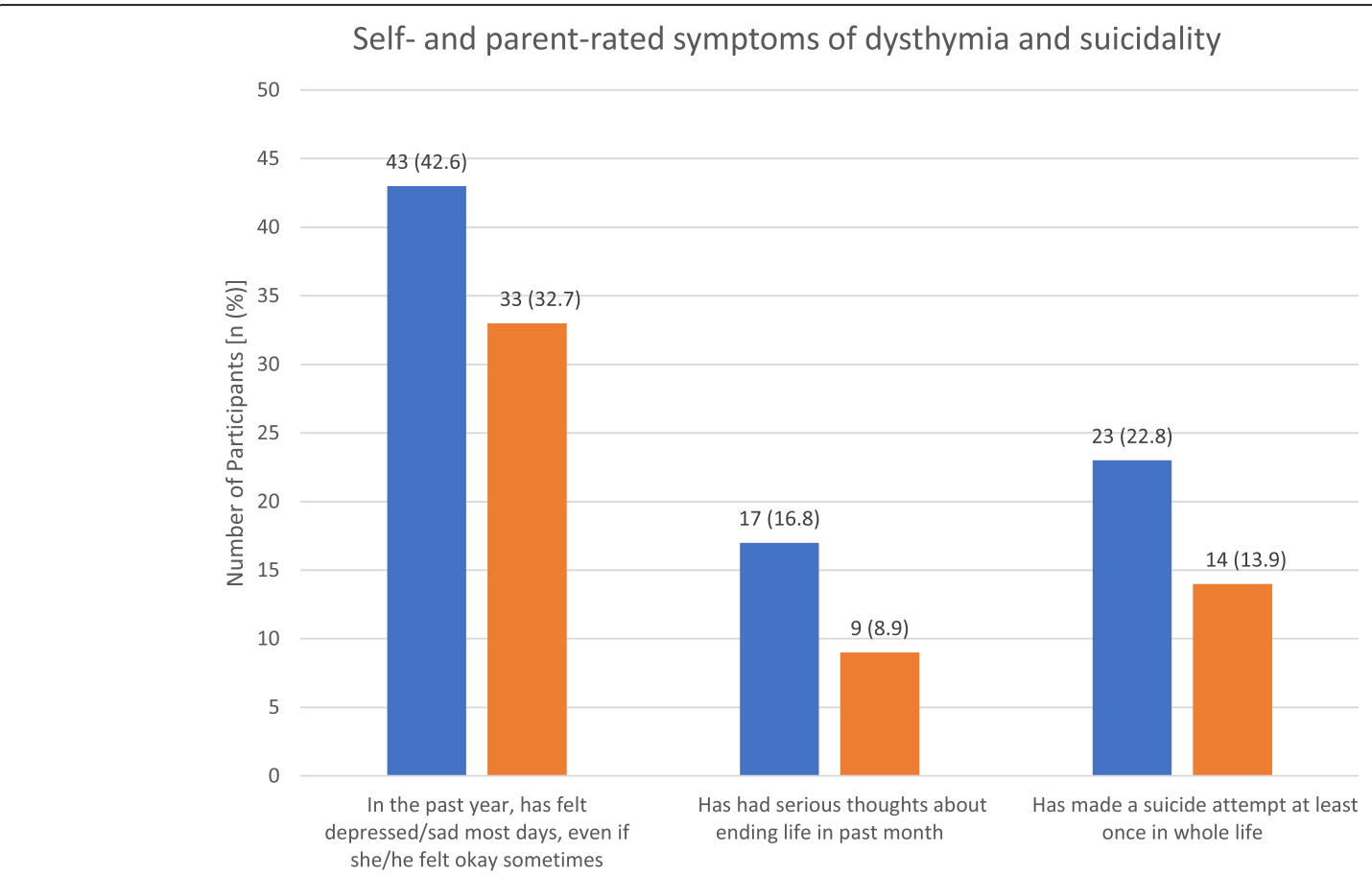

Fig. 3 Self- and parent-rated symptoms of dysthymia during the past year $(p=0.1228)$, suicidal thoughts in the previous month $(p=0.0522)$ and attempted suicide at least once in lifetime $(p=0.0495) . n=101$. Data contributed by author

this sample, 37\% had associated psychotic symptoms and/or suicidality (Fig. 1). The high rate of depression may be attributed to ASD-related social issues, such as peer victimization [22], social difficulties [23, 24], impaired ability to emotionally adapt to perceived social failures [25], greater loneliness [26], poorer quality of life [27] and lack of friendships [28] compared to neurotypical peers. Additionally, autistic individuals may engage in greater use of maladaptive forms of emotional regulation, such as rumination and shutting down (e.g.

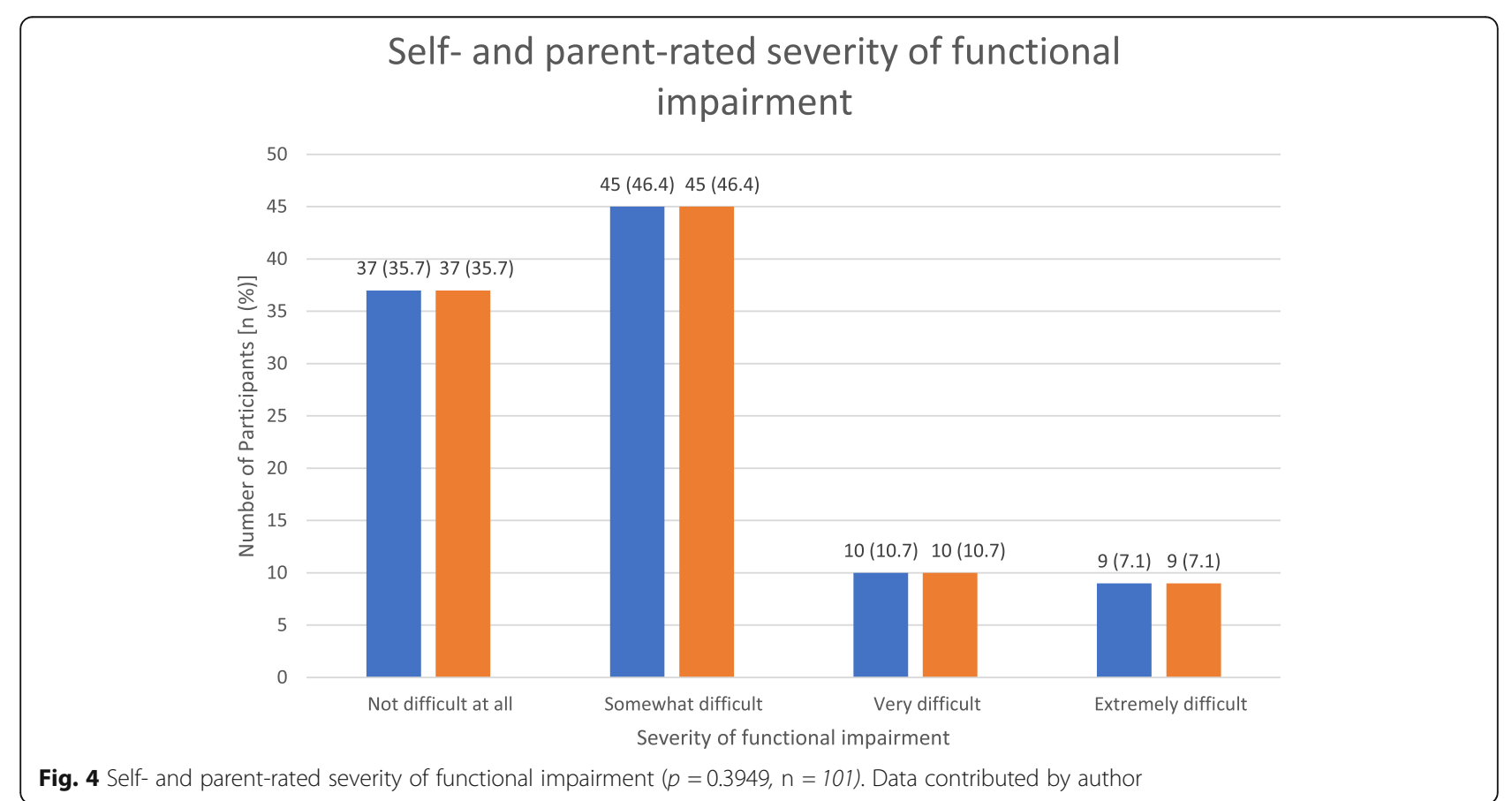


Table 2 Sensitivity, specificity, and positive and negative predictive values for a diagnosis MDD across various cutoffs of the PHQ-9 $(n=101)$

\begin{tabular}{|c|c|c|c|c|c|}
\hline Cutoff Score & Sensitivity (\%) & Specificity (\%) & Positive Predictive Value (\%) & Negative Predictive Value (\%) & Youden's Index \\
\hline \multicolumn{6}{|l|}{ Self-rated } \\
\hline 3 & 100.0 & 19.5 & 22.4 & 100.0 & 0.195 \\
\hline 4 & 100.0 & 25.6 & 23.8 & 100.0 & 0.256 \\
\hline 5 & 100.0 & 35.4 & 26.4 & 100.0 & 0.354 \\
\hline 6 & 89.5 & 37.8 & 25.0 & 93.9 & 0.273 \\
\hline 7 & 78.9 & 43.9 & 24.6 & 90.0 & 0.229 \\
\hline 8 & 78.9 & 50.0 & 26.8 & 91.1 & 0.289 \\
\hline 9 & 73.7 & 56.1 & 28.0 & 90.2 & 0.298 \\
\hline 10 & 68.4 & 58.5 & 27.7 & 88.9 & 0.270 \\
\hline 11 & 63.2 & 63.4 & 28.6 & 88.1 & 0.266 \\
\hline 12 & 63.2 & 70.7 & 33.3 & 89.2 & 0.339 \\
\hline 13 & 57.9 & 75.6 & 35.5 & 88.6 & 0.335 \\
\hline 14 & 47.4 & 79.3 & 34.6 & 86.7 & 0.266 \\
\hline 15 & 36.8 & 85.4 & 36.8 & 85.4 & 0.222 \\
\hline \multicolumn{6}{|l|}{$\underline{\text { Parent-rated }}$} \\
\hline 3 & 78.9 & 34.1 & 21.7 & 87.5 & 0.131 \\
\hline 4 & 78.9 & 40.2 & 23.4 & 89.2 & 0.192 \\
\hline 5 & 73.7 & 50.0 & 25.5 & 89.1 & 0.237 \\
\hline 6 & 73.7 & 58.5 & 29.2 & 90.6 & 0.322 \\
\hline 7 & 57.9 & 64.6 & 27.5 & 86.9 & 0.225 \\
\hline 8 & 47.4 & 73.2 & 29.0 & 85.7 & 0.205 \\
\hline 9 & 47.4 & 75.6 & 31.0 & 86.1 & 0.230 \\
\hline 10 & 42.1 & 78.0 & 30.8 & 85.3 & 0.202 \\
\hline 11 & 36.8 & 80.5 & 30.4 & 84.6 & 0.173 \\
\hline 12 & 31.6 & 84.1 & 31.6 & 84.1 & 0.157 \\
\hline
\end{tabular}

Grey: the proposed cutoff. Orange: the statistically optimal cutoff based on the Youden's Index. Data contributed by author

emotional numbing) [29], which are highly associated with the development of depression and anxiety.

Similar to previous literature $[7,8]$, the number of comorbidities was found to be positively correlated to selfreported functional impairment $\left(r_{s}=0.338 ; p=0.01\right)$ and depressive symptoms $\left(r_{s}=0.327 ; p=0.01\right)$; this suggests that effective treatment of comorbid psychiatric issues may be important for a holistic approach to depression in autistic youth.

Although the PHQ-9 has been shown to have similar psychometric properties within both the autism and community sample aged $15-80$ years old, indicating its usefulness in measuring depression in ASD individuals in that age group [13], our study found it to be a less than ideal screening tool for MDD in autistic youths. High sensitivity is of primary concern in determining the clinical utility of depression screens when false negative outcomes can mean morbidity and fatality. Using the conventional cutoff of 11 for the self- and parent-rated PHQ-9 in autistic youth in this study yielded lower sensitivities and specificities than for neuro-typical adolescents [11] (Table 2). The statistically optimal cutoffs based on the YI for the self- and parent-rated PHQ-9 are 5 and 6 , respectively. However, despite these adjustments, the parent- and self-rated PHQ-9 would still be inappropriate depression screens. A sensitivity of $73.7 \%$ for a cutoff of 6 in the parent-rated PHQ-9 would lead to a high false positive (58.5\% specificity) and negative rate. Even if sensitivity was increased to $78.9 \%$ by decreasing the cutoff to 4 , the specificity decreases even lower to $40.2 \%$. On the other hand, a self-rated PHQ-9 cutoff of 5 yields $100 \%$ sensitivity, but an even higher false positive rate (26.4\% specificity). A proposed cutoff of 8 would only minimally increase specificity to $50.0 \%$ while compromising sensitivity to $78.9 \%$. Nonetheless our results show relatively poor specificity compared to sensitivity at the adjusted cutoffs for both self- and parent-rated PHQ-9 in detecting MDD in autistic youths, indicating that the PHQ-9 would be relatively better at 'ruling out' MDD than 'ruling in'. Hence, a 

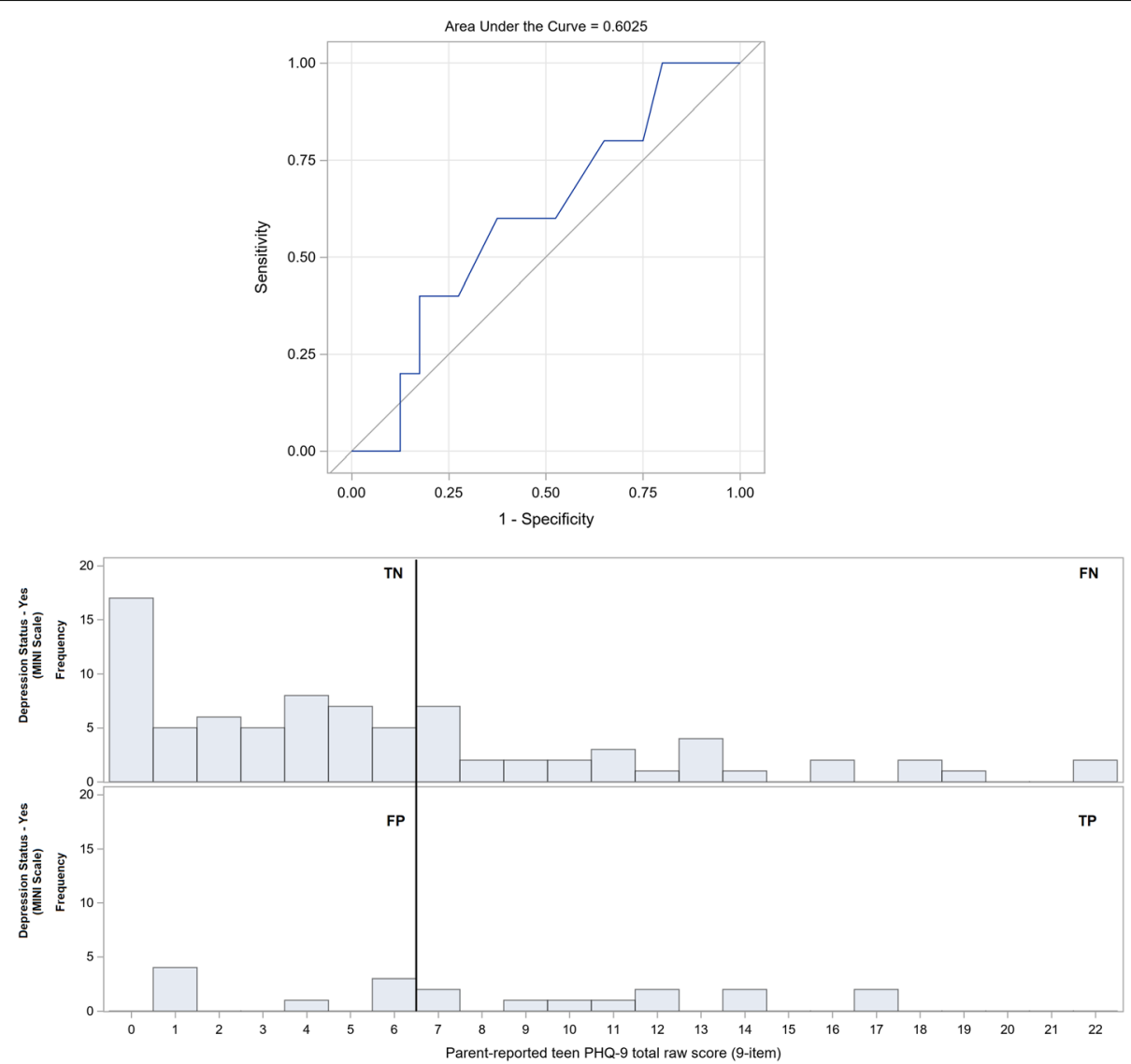

Fig. 5 ROC curve (above) of parent-rated PHQ-9 for detecting MDD (AUC: 0.653, 95\% Cl: 0.521-0.784, $p=0.094$ ) and corresponding histogram (below). PHQ-9, nine-item teen Patient Health Questionnaire; ROC, receiver operating characteristic; TN, true negative; FN, false negative; FP, false positive; TP, true positive. Data contributed by author

positive screen on the PHQ-9 could be followed up with a formal supplementary evaluation by a specialist familiar with the manifestation of depression in autistic youths.

Other studies also found relatively poor specificity compared to sensitivity in detecting co-occurring emotional problems in autistic youths at established optimal cutoffs [8]. These findings may be due to depressive symptoms overlapping with baseline characteristics of ASD itself $[14,30]$, making it difficult to distinguish between the two. Another possible reason for the lack of specificity is the high co-occurrence of other psychiatric comorbidities in ASD, which could account for some symptoms in the PHQ-9 [31].

Possible reasons for lower PHQ-9 cutoffs for autistic youth compared to neuro-typical adolescents are: 1) emotional states not being congruent to what is observed, 2) PHQ-9 not fully capturing the manifestation of depression in autism, 3) alexithymia in ASD [32] and/ or 4) difficulty interpreting questions asked [33]. Previous literature suggest that individuals with ASD find identifying, processing [34], regulating [29], and communicating [35] emotions challenging. They also often have marked impairment in the quality of the affect-showing facial expressions that are neutral and difficult to interpret-and disengagement that could mute the association with depressive symptoms [29]. Inadequate emotional regulation abilities could predispose them to rapid escalation of reactions that are out of proportion to what is typically experienced. Taken together with poorer and unconventional communication skills, these could have resulted in depression, despite a lower PHQ-9 score. Another possibility for a lower score is that ASD-specific symptoms, such as changes in repetitive and stereotypic behaviors, are not accounted for. Hence, it may be difficult for current tools to fully capture depression experienced by ASD youth. A screen that incorporates an evaluation of change in clinical symptoms of ASD during the onset of depression, such as intensification of social withdrawal and ritualistic behavior/obsessions coupled with associated features, such as irritability, compulsivity, hyperactivity and decreased adaptive functioning, [30, 36] may be a helpful and appropriate alternative. 

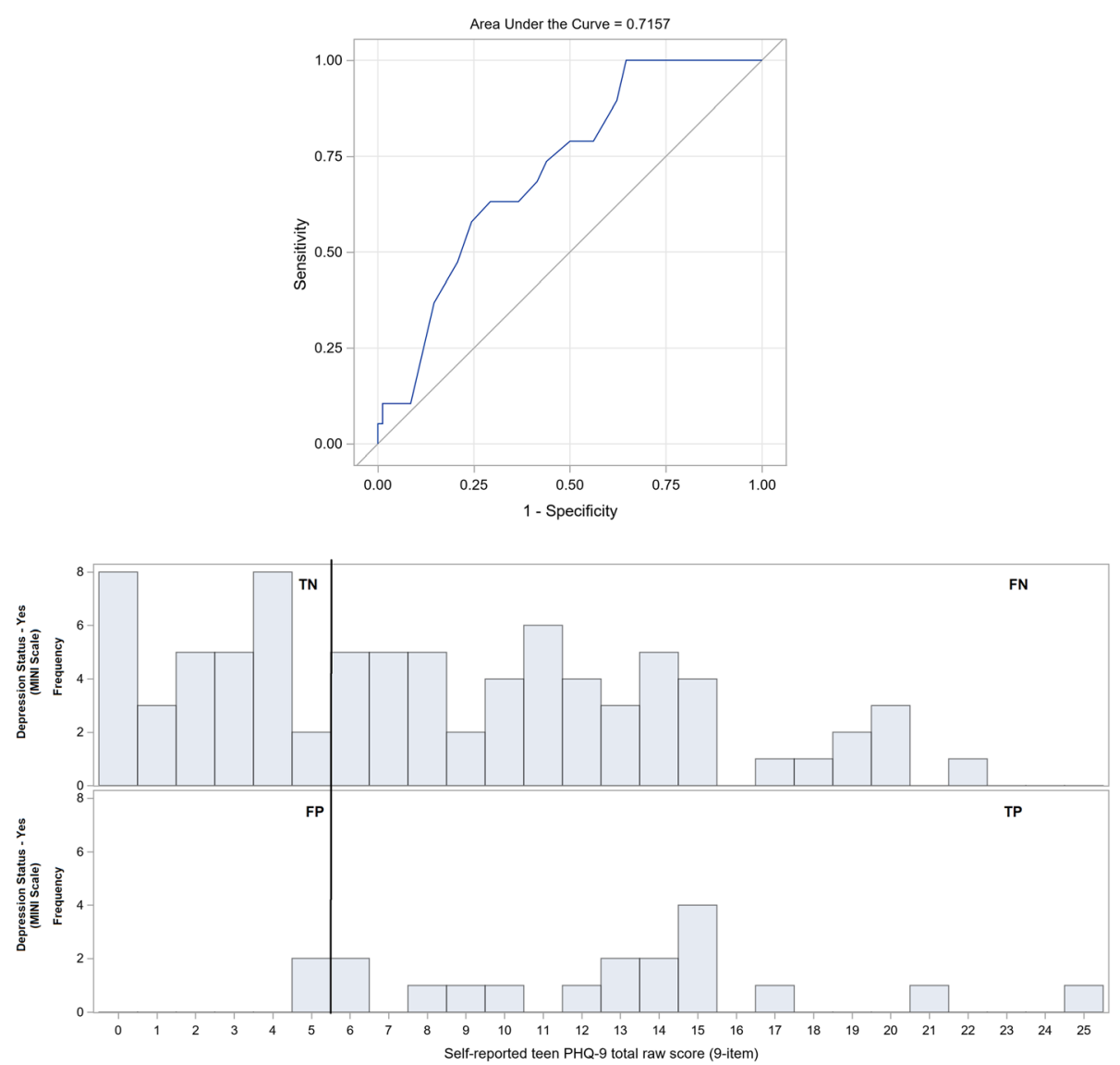

Fig. 6 ROC curve of self-rated PHQ-9 for detecting MDD (AUC =0.716, 95\% Cl: 0.600-0.831, $p=0.007$ ) (above) and corresponding histogram (below). PHQ-9, nine-item teen Patient Health Questionnaire; ROC, receiver operating characteristic; TN, true negative; FN, false negative; FP, false positive; TP, true positive. Data contributed by author

Possible reasons for the discrepancy between the parent- and self-rated adjusted cutoffs could be related to parents' under-detection of depressive symptoms in autistic youth and cultural stigma around mental illness $[12,37]$. Our findings indicate almost twice as many youth rating their depressive symptoms as moderate, moderately severe, and severe compared to their parents; this under-reporting by parents is consistent with previous studies [38]. Parents may be less forthcoming when reporting depressive symptoms, less inclined to discuss

Table 3 Spearman correlation coefficients for associations between self- and parent-rated severity of depressive symptoms and of functional impairment, and number of comorbidities $(n=101)$

\begin{tabular}{|c|c|c|c|c|c|c|}
\hline & & \multicolumn{2}{|c|}{ Self-reported severity } & \multicolumn{2}{|c|}{ Parent-reported severity } & \multirow{2}{*}{$\begin{array}{l}\text { No. of } \\
\text { comorbidities }\end{array}$} \\
\hline & & $\begin{array}{l}\text { Functional } \\
\text { impairment }\end{array}$ & $\begin{array}{l}\text { Depressive } \\
\text { symptoms }\end{array}$ & $\begin{array}{l}\text { Functional } \\
\text { impairment }\end{array}$ & $\begin{array}{l}\text { Depressive } \\
\text { symptoms }\end{array}$ & \\
\hline \multirow[t]{2}{*}{ Self-rated severity } & $\begin{array}{l}\text { Functional } \\
\text { impairment }\end{array}$ & & $0.534^{* *}$ & $0.287^{* *}$ & $0.252^{*}$ & $0.338^{* *}$ \\
\hline & $\begin{array}{l}\text { Depressive } \\
\text { symptoms }\end{array}$ & $0.534^{* *}$ & & $0.428^{* *}$ & $0.410^{* *}$ & $0.327^{* *}$ \\
\hline \multirow[t]{2}{*}{$\frac{\text { Parent-rated }}{\underline{\text { severity }}}$} & $\begin{array}{l}\text { Functional } \\
\text { impairment }\end{array}$ & $0.287^{* *}$ & $0.428^{* *}$ & & $0.583^{* *}$ & $0.285^{* *}$ \\
\hline & $\begin{array}{l}\text { Depressive } \\
\text { symptoms }\end{array}$ & $0.252^{*}$ & $0.410^{* *}$ & $0.583^{* *}$ & & $0.307^{* *}$ \\
\hline \multicolumn{2}{|c|}{ No. of comorbidities } & $0.338^{* *}$ & $0.327^{* *}$ & $0.285^{* *}$ & $0.307^{* *}$ & \\
\hline
\end{tabular}

${ }^{* *}$ Correlation significant at $p=0.01$ level (2-tailed)

${ }^{*}$ Correlation significant at $p=0.05$ level (2-tailed) 
depression with their child, or simply may not be aware of the indications of depression. Parents may also interpret these symptoms as temporary variations in typical autistic behavior. In this regard, if the autistic youth selfreports depressive symptoms that are significant while their parent does not, it may be prudent to evaluate the case further regardless.

Our study result is preliminary, and our sample size may be too small to support definitive conclusions. Replication of our analyses and evaluation of psychometric properties of the PHQ-9 on a larger and more diverse sample with variables that could be related to depression in autistic youth can improve our understanding of the appropriate uses and interpretations of the PHQ-9 in specific subgroups within the autistic population. For example, males with ASD are found to have more externalizing behavior problems [39] and less internalizing symptoms [40] than females, potentially leading to positively skewed results. Further studies should also explore how depression may present in those with lower communication and cognitive abilities, as these factors could have variably affected and influenced our results. Additionally, $46 \%$ of our patients were on psychotropic medications at the time of enrollment, which could affect the presentation of depression. Those on antidepressants for more extended periods may have less florid depressive symptoms and functional impairment, while those on other psychotropic medications, such as anxiolytics or stimulants, may have had medically-induced subthreshold depressive symptoms. There is also a possibility of recall bias when interviewing autistic participants about MDEs and symptoms of other psychiatric comorbidities. For example, since this population may have a greater tendency to ruminate over past negative experiences [41], reported depressive symptoms/recollections might extend beyond the previous two weeks indicated for diagnosis. Controlling for the impact of confounding factors such as psychotropic medications, sex, ethnicity, age, comorbidities and history of previous MDEs in future studies [42] is recommended.

Future studies could also examine the influence of clinical severity profile of participants' ASD and its consequential functional impairments, on the presentation of co-occurring depression. Severe impairment in social skills may lead to increased dysfunction in interpersonal relationships and negative life events, precipitating relatively more depressive symptoms. On the other hand, severe ASD symptoms could mask the manifestation of depression symptoms, resulting in under-reporting in both youths and parents, or a missed diagnosis by the clinician. A depression screening scale that takes into account the severity of ASD symptoms and corresponding changes would be useful to determine the presentation, and severity of presentation of depression in individuals with ASD.

\section{Conclusion}

Due to the high co-occurrence of depression in autistic youth, routine screening, exploration of functional impairment, and effective treatment of other comorbid psychiatric issues should be conducted to allow for early multidisciplinary intervention, and minimization of associated morbidity and suicide risk. Although our study found low sensitivities with unacceptably high false negative rates using conventional, statistically optimal, and proposed cutoffs for the parent- and self-rated PHQ-9, the small sample size does not allow definitive cutoffs to be made with confidence. The discrepancy between proposed parent- and self-rated cutoffs indicate that interpretations based on a single source may be inconclusive and require additional evaluation by a specialist. Fundamentally, it is difficult to evaluate depression in the autistic population as 1) patients may have difficulty in communicating and understanding how they feel, and 2) behaviors suggesting a depressive disorder in ASD have yet to be clearly identified [14, 30]. Future studies should improve on the validity and reliability of existing screening tools, or explore and develop more appropriate screening methods for depression in autistic youths.

\section{Abbreviations}

ASD: Autism Spectrum Disorder; AUC: area under the curve; CELF-5: Clinical Evaluation of Language Fundamentals, 5th Edition, Screening Tool;

CGC: Child Guidance Clinic; CRC Ref: Clinical Research Committee Reference; DSM-5: Diagnostic and Statistical Manual, 5th Edition; DSMIV: Diagnostic and Statistical Manual, 4th Edition; DSRB Ref: Domain Specific Review Board Reference; FN: false negative; FP: false positive; TN: true negative; TP: true positive; IMH: Institute of Mental Health; MINI-Kid: Mini-International Neuropsychiatric Interview, Kid version; MDD: Major Depressive Disorder; MDE: Major Depressive Episode; NPV: negative predictive value; PHQ9: Patient Health Questionnaire 9-item; PPV: positive predictive value; ROC: Receiver Operating Characteristic; YI: Youden Index

\section{Acknowledgements}

We thank the families and patients who participated in this research, and the research team members, psychiatrists, psychologists and medical social workers of the Child Guidance Clinic, IMH, Singapore. The study was funded by the Institutional Research Grant, Institute of Mental Health, Singapore, Reference: CRC 612/2018.

\section{Conflict of interest}

The authors have indicated they have no potential conflicts of interest and financial relationships relevant to this article to disclose.

\section{Authors' contributions}

All authors made substantial contributions in drafting and critically revising the content of the paper. TP contributed in conceptualizing and designing the study, and in data acquisition, analysis and interpretation. TJG contributed in conceptualizing and designing the study, as well as data interpretation. MS and DSSF contributed in conceptualizing, designing and supervising the study. RS and JCA contributed in data analysis and interpretation. All authors approved the final manuscript as submitted and agree to be accountable for all aspects of the work. 


\section{Funding}

All phases of this study were supported by the Institutional Research Grant, Institute of Mental Health, Singapore, Reference: CRC 612/2018. Funding was used for participants' inconvenience fees, stationary and printing of flyers, and purchasing the CELF-5 screening tool to assess participants' eligibility for the study. The funding body was not involved in the design and collection, analysis and interpretation of data, and in writing the manuscript.

\section{Availability of data and materials}

The datasets used and/or analyzed during the current study are available from the corresponding author on reasonable request.

\section{Declarations}

\section{Ethics approval and consent to participate}

Ethics approval was obtained from the IMH Institutional Research Review Committee and (CRC 612/2018) and National Healthcare Group Domain Specific Review Board (NHG DSRB 2018/00352). The procedures used in this study adhere to the tenets of the Declaration of Helsinki. Written informed consent to participate in the study was obtained from all individual participants prior to conducting the study, including from parents or guardians of participants under 16 years old.

\section{Consent for publication}

Not applicable.

\section{Competing interests}

The authors declare that they have no competing interests.

\section{Author details}

'Ministry of Health, 16 College Rd, College of Medicine Building, Singapore 169854, Singapore. ${ }^{2}$ Department of Child \& Adolescent Psychiatry, Institute of Mental Health, Buangkok Green Medical Park, 10 Buangkok View, Singapore 539747, Singapore. ${ }^{3}$ Duke-NUS Medical School, 18 College Rd, Singapore 169857, Singapore.

Received: 8 July 2021 Accepted: 20 October 2021

\section{Published online: 12 November 2021}

\section{References}

1. Hudson CC, Hall L, Harkness KL. Prevalence of depressive disorders in individuals with autism Spectrum disorder: a Meta-analysis. J Abnorm Child Psychol. 2019;47(1):165-75. https://doi.org/10.1007/s10802-018-0402-1.

2. Lugnegard T, Hallerback MU, Gillberg C. Psychiatric comorbidity in young adults with a clinical diagnosis of Asperger syndrome. Res Dev Disabil. 2011; 32(5):1910-7. https://doi.org/10.1016/j.ridd.2011.03.025.

3. Mukaddes NM, Fateh R. High rates of psychiatric co-morbidity in individuals with Asperger's disorder. World J Biol Psychiatry. 2010;11(2 Pt 2):486-92. https://doi.org/10.3109/15622970902789130.

4. Garg P, Lillystone D, Dossetor D, Wilkinson H, Kefford C, Eastwood J, et al. A Framework for Developing a Curriculum Regarding Autism Spectrum Disorders for Primary Care Providers. J Clin Diagn Res: JCDR. 2015:9(10):Sc01-6.

5. Findon J, Cadman $\mathrm{T}$, Stewart CS, Woodhouse $\mathrm{E}$, Eklund $\mathrm{H}$, Hayward $\mathrm{H}$, et al. Screening for co-occurring conditions in adults with autism spectrum disorder using the strengths and difficulties questionnaire: a pilot study. Autism Res. 2016;9(12):1353-63. https://doi.org/10.1002/aur.1625.

6. Gotham K, Brunwasser SM, Lord C. Depressive and Anxiety Symptom Trajectories From School-Age Through Young Adulthood in Samples With Autism Spectrum Disorder and Developmental Delay. J Am Acad Child Adolesc Psychiatry. 2015;54(5):369-76.e3.

7. Leyfer OT, Folstein SE, Bacalman S, Davis NO, Dinh E, Morgan J, et al. Comorbid psychiatric disorders in children with autism: interview development and rates of disorders. J Autism Dev Disord. 2006;36(7):849_ 61. https://doi.org/10.1007/s10803-006-0123-0.

8. Pandolfi V, Magyar Cl, Dill CA. An initial psychometric evaluation of the CBCL 618 in a sample of youth with autism Spectrum disorders. Res Autism Spectr Disord. 2012;6(1):96-108. https://doi.org/10.1016/j.rasd.2011.03.009

9. Levis B, Benedetti A, Riehm KE, Saadat N, Levis AW, Azar M, et al. Probability of major depression diagnostic classification using semi-structured versus fully structured diagnostic interviews. Br J Psychiatry. 2018;212(6):377-85. https://doi.org/10.1192/bjp.2018.54.
10. Levis B, Benedetti A, Thombs BD. Accuracy of patient health Questionnaire-9 (PHQ-9) for screening to detect major depression: individual participant data meta-analysis. BMJ. 2019;365:11476. https:// doi.org/10.1136/bmj.|1476.

11. Richardson LP, McCauley E, Grossman DC, McCarty CA, Richards J, Russo JE, et al. Evaluation of the patient health Questionnaire-9 item for detecting major depression among adolescents. Pediatrics. 2010;126(6):1117-23. https://doi.org/10.1542/peds.2010-0852.

12. Sung SC, Low CC, Fung DS, Chan YH. Screening for major and minor depression in a multiethnic sample of Asian primary care patients: a comparison of the nine-item Patient Health Questionnaire (PHQ-9) and the 16-item Quick Inventory of Depressive Symptomatology - Self-Report (QIDSSR16). Asia Pac Psychiatry. 2013;5(4):249-58. https://doi.org/10.1111/a ppy.12101.

13. Arnold SRC, Uljarevic M, Hwang Yl, Richdale AL, Trollor JN, Lawson LP. Brief report: psychometric properties of the patient health Questionaire-9 (PHQ-9) in autistic adults. J Autism Dev Disord. 2019;50(6):2217-25. https://doi.org/1 0.1007/s10803-019-03947-9.

14. Stewart ME, Barnard L, Pearson J, Hasan R, O'Brien G. Presentation of depression in autism and Asperger syndrome: a review. Autism Int J Res Pract. 2006;10(1):103-16. https://doi.org/10.1177/1362361306062013.

15. Coret MC, McCrimmon AW. Test Review: Wiig, E. H., Semel, E., \& Secord, W. A. (2013). Clinical Evaluation of Language Fundamentals-Fifth Edition (CELF5). J Psychoeduc Assess. 2015;33(5):495-500.

16. Spitzer RL, Kroenke K, Williams JB. Validation and utility of a self-report version of PRIME-MD: the PHQ primary care study. Primary care evaluation of mental disorders. Patient health questionnaire. JAMA. 1999;282(18):173744. https://doi.org/10.1001/jama.282.18.1737.

17. Sheehan DV, Sheehan KH, Shytle RD, Janavs J, Bannon Y, Rogers JE, et al. Reliability and validity of the Mini international neuropsychiatric interview for children and adolescents (MINI-KID). J Clin Psychiatry. 2010;71(3):313-26. https://doi.org/10.4088/JCP.09m05305whi.

18. Brookman-Frazee L, Stadnick N, Chlebowski C, Baker-Ericzén M, Ganger W. Characterizing psychiatric comorbidity in children with autism spectrum disorder receiving publicly funded mental health services. Autism Int J Res Pract. 2017:22(8):938-52. https://doi.org/10.1177/1362361317712650.

19. Sreedaran P, Ashok MV. Asperger syndrome in India: findings from a caseseries with respect to clinical profile and comorbidity. Indian J Psychol Med. 2015;37(2):212-4. https://doi.org/10.4103/0253-7176.155632.

20. Schroeder J, Weiss J, Bebko J. CBCL Profiles of Children and Adolescents with Asperger Syndrome: A Review and Pilot Study. J Dev Disabil. 2011;17.

21. Mazefsky CA, Anderson R, Conner CM, Minshew N. Child behavior checklist scores for school-aged children with autism: preliminary evidence of patterns suggesting the need for referral. J Psychopathol Behav Assess. 2011:33(1):31-7. https://doi.org/10.1007/s10862-010-9198-1.

22. Segers M, Rawana J. What do we know about suicidality in autism spectrum disorders? A systematic review. Autism Res. 2014;7(4):507-21. https://doi. org/10.1002/aur.1375.

23. Barnhill GP. Social attributions and depression in adolescents with Asperger syndrome. Focus Autism Other Dev Disabil. 2001;16(1):46-53. https://doi. org/10.1177/108835760101600112.

24. Vickerstaff S, Heriot S, Wong M, Lopes A, Dossetor D. Intellectual ability, selfperceived social competence, and depressive symptomatology in children with high-functioning autistic spectrum disorders. J Autism Dev Disord. 2007:37(9):1647-64. https://doi.org/10.1007/s10803-006-0292-x.

25. Howlin P. Outcome in adult life for more able individuals with autism or Asperger syndrome. Autism Int J Res Pract. 2000;4(1):63-83. https://doi.org/1 $0.1177 / 1362361300004001005$

26. Clarke T, Tickle A, Gillott A. Substance use disorder in Asperger syndrome: an investigation into the development and maintenance of substance use disorder by individuals with a diagnosis of Asperger syndrome. Int J Drug Policy. 2016;27:154-63. https://doi.org/10.1016/j.drugpo.2015.06.003.

27. Schmidt L, Kirchner J, Strunz S, Brozus J, Ritter K, Roepke S, et al. Psychosocial functioning and life satisfaction in adults with autism Spectrum disorder without intellectual impairment. J Clin Psychol. 2015; 71(12):1259-68. https://doi.org/10.1002/jclp.22225.

28. Bauminger $\mathrm{N}$, Kasari C. Loneliness and friendship in high-functioning children with autism. Child Dev. 2000;71(2):447-56. https://doi.org/1 $0.1111 / 1467-8624.00156$

29. Mazefsky CA, Borue $X$, Day TN, Minshew NJ. Emotion regulation patterns in adolescents with high-functioning autism spectrum disorder: comparison to 
typically developing adolescents and association with psychiatric symptoms Autism Res. 2014;7(3):344-54. https://doi.org/10.1002/aur.1366.

30. Magnuson KM, Constantino JN. Characterization of depression in children with autism spectrum disorders. J Dev Behav Pediatr. 2011;32(4):332-40. https://doi.org/10.1097/DBP.0b013e318213f56c.

31. Taurines R, Schwenck C, Westerwald E, Sachse M, Siniatchkin M, Freitag C. ADHD and autism: differential diagnosis or overlapping traits? A selective review. Atten Defic Hyperact Disord. 2012;4(3):115-39. https://doi.org/10.1 007/s12402-012-0086-2.

32. Fiene L, Ireland MJ, Brownlow C. The Interoception sensory questionnaire (ISQ): a scale to measure interoceptive challenges in adults. J Autism Dev Disord. 2018;48(10):3354-66. https://doi.org/10.1007/s10803-018-3600-3.

33. Cassidy SA, Bradley L, Bowen E, Wigham S, Rodgers J. Measurement properties of tools used to assess depression in adults with and without autism spectrum conditions: a systematic review. Autism Res. 2018;11(5): 738-54. https://doi.org/10.1002/aur.1922.

34. Dijkhuis RR, Ziermans TB, Van Rijn S, Staal WG, Swaab H. Self-regulation and quality of life in high-functioning young adults with autism. Autism Int J Res Pract. 2017;21(7):896-906. https://doi.org/10.1177/1362361316655525.

35. Scheeren AM, Koot HM, Mundy PC, Mous L, Begeer S. Empathic responsiveness of children and adolescents with high-functioning autism spectrum disorder. Autism Res. 2013;6(5):362-71. https://doi.org/10.1002/a ur.1299.

36. Pollard AJ, Prendergast M. Depressive pseudodementia in a child with autism. Dev Med Child Neurol. 2004;46(7):485-9. https://doi.org/10.1017/ s0012162204000805.

37. Yuan $Q$, Abdin E, Picco L, Vaingankar JA, Shahwan S, Jeyagurunathan A, et al. Attitudes to mental illness and its demographic correlates among general population in Singapore. PLoS One. 2016;11(11):e0167297. https:// doi.org/10.1371/journal.pone.0167297.

38. Hurtig T, Kuusikko S, Mattila ML, Haapsamo H, Ebeling H, Jussila K, et al. Multi-informant reports of psychiatric symptoms among high-functioning adolescents with Asperger syndrome or autism. Autism Int J Res Pract. 2009; 13(6):583-98. https://doi.org/10.1177/1362361309335719.

39. Mandy W, Chilvers R, Chowdhury U, Salter G, Seigal A, Skuse D. Sex differences in autism spectrum disorder: evidence from a large sample of children and adolescents. J Autism Dev Disord. 2012;42(7):1304-13. https:// doi.org/10.1007/s10803-011-1356-0.

40. Solomon M, Miller M, Taylor SL, Hinshaw SP, Carter CS. Autism symptoms and internalizing psychopathology in girls and boys with autism spectrum disorders. J Autism Dev Disord. 2012;42(1):48-59. https://doi.org/10.1007/s1 0803-011-1215-z

41. Gotham K, Bishop SL, Brunwasser S, Lord C. Rumination and perceived impairment associated with depressive symptoms in a verbal adolescentadult ASD sample. Autism Res. 2014;7(3):381-91. https://doi.org/10.1002/a ur.1377.

42. Pourhoseingholi MA, Baghestani AR, Vahedi M. How to control confounding effects by statistical analysis. Gastroenterol Hepatol From Bed to Bench. 2012;5(2):79-83.

\section{Publisher's Note}

Springer Nature remains neutral with regard to jurisdictional claims in published maps and institutional affiliations.

Ready to submit your research? Choose BMC and benefit from:

- fast, convenient online submission

- thorough peer review by experienced researchers in your field

- rapid publication on acceptance

- support for research data, including large and complex data types

- gold Open Access which fosters wider collaboration and increased citations

- maximum visibility for your research: over $100 \mathrm{M}$ website views per year

At BMC, research is always in progress.

Learn more biomedcentral.com/submissions 